\title{
Zinc and di-iodohydroxyquinoline therapy in acrodermatitis enteropathica
}

\author{
MALCOLM J. JACKSON \\ From the Metabolic Ward, University College Hospital, London WC1
}

SUMMARY A 25-year-old patient with acrodermatitis enteropathica who had been treated with di-iodohydroxyquinoline for 20 years was changed to zinc sulphate therapy and studied under full metabolic balance control for zinc, calcium, magnesium, and inorganic phosphorus. The results obtained indicate that there is only a small overall deficit of body zinc stores in this disease and that the function of di-iodohydroxyquinoline is to increase the amount of zinc absorbed and retained by the body.

It has been shown that acrodermatitis enteropathica is an inherited zinc deficiency disorder (Barnes and Moynahan, 1973; Moynahan, 1975; Neldner and Hambidge, 1975)| but, the mechanism by which this deficiency occurs has not been satisfactorily ascertained. Lombeck et al. (1975), in acute loading tests, showed that the defect was a reduced absorption of zinc by the gut and not an increased excretion of zinc into faeces, urine or sweat. It was postulated by Moynahan (1974) that an oligopeptide chelated the ingested zinc to yield an insoluble complex, thus reducing the zinc available for absorption. Recently, Delves et al. (1975) have suggested that di-iodohydroxyquinoline acts by complexing the zinc ions and this complex is absorbed from the gut. External zinc balances before and after change of treatment do not appear to have been described. The aim of this work was to obtain information on the mechanism of the therapeutic effect of di-iodohydroxyquinoline in this disease and to obtain a measure of the deficiency of zinc in this patient.

\section{Patient}

Our patient was a woman who had been diagnosed by Hare and Schlesinger (1955), at which time she had been started on di-iodohydroxyquinoline therapy, a gluten-free diet, and pancreatin. She was kept on regular follow-up, and six months later the gluten-

Received for publication 14 July 1976 free diet and pancreatin were stopped. She had been on a variable dose of di-iodohydroxyquinoline (from 600 to $2400 \mathrm{mg} /$ day) until April 1975 at which time the present study began.

Her rash had tended to recur at varying times for no apparent reason, and at such times it had been necessary to raise her dose of di-iodohydroxyquinoline. She had normal mental and physical development during this period and the only remaining disease complication was some minimal corneal scarring.

After her marriage in 1972 she began taking the contraceptive pill Minovlar (Schering Chemicals Ltd) and four months later her dose of di-iodohydroxyquinoline had to be increased from 1200 to $1500 \mathrm{mg} /$ day. One year later this was raised to $1800 \mathrm{mg} /$ day due to continued deterioration in the condition of her skin. In February 1975 the contraceptive pill was changed to Minilyn (Organon Laboratories Ltd) and at this time the plasma and urine zinc were first measured. The plasma zinc was $3.2 \mu \mathrm{M} / 1$ (normal range 11.5-17.6 $\mu \mathrm{M} / \mathrm{l}$ ) and the urinary zinc was found to be $2.9 \mu \mathrm{M} / 24 \mathrm{~h}$ (normal range 7·0-15.0 $\mu \mathrm{M} / 24 \mathrm{~h}$ ). In March 1975 the contraceptive pill was stopped and the patient voluntarily entered the Metabolic Ward of University College Hospital in order to have her treatment changed to zinc sulphate. It had been noted that for the past 10 years she had had a consistently high urine calcium (greater than $7.5 \mathrm{mM} / 24 \mathrm{~h}$ ) and because of the intrinsic requirement for zinc in the osteogenesis of bone (Calhoun et al., 1974) she was studied under full metabolic balance control for zinc, calcium, magnesium, and inorganic phosphorus. 


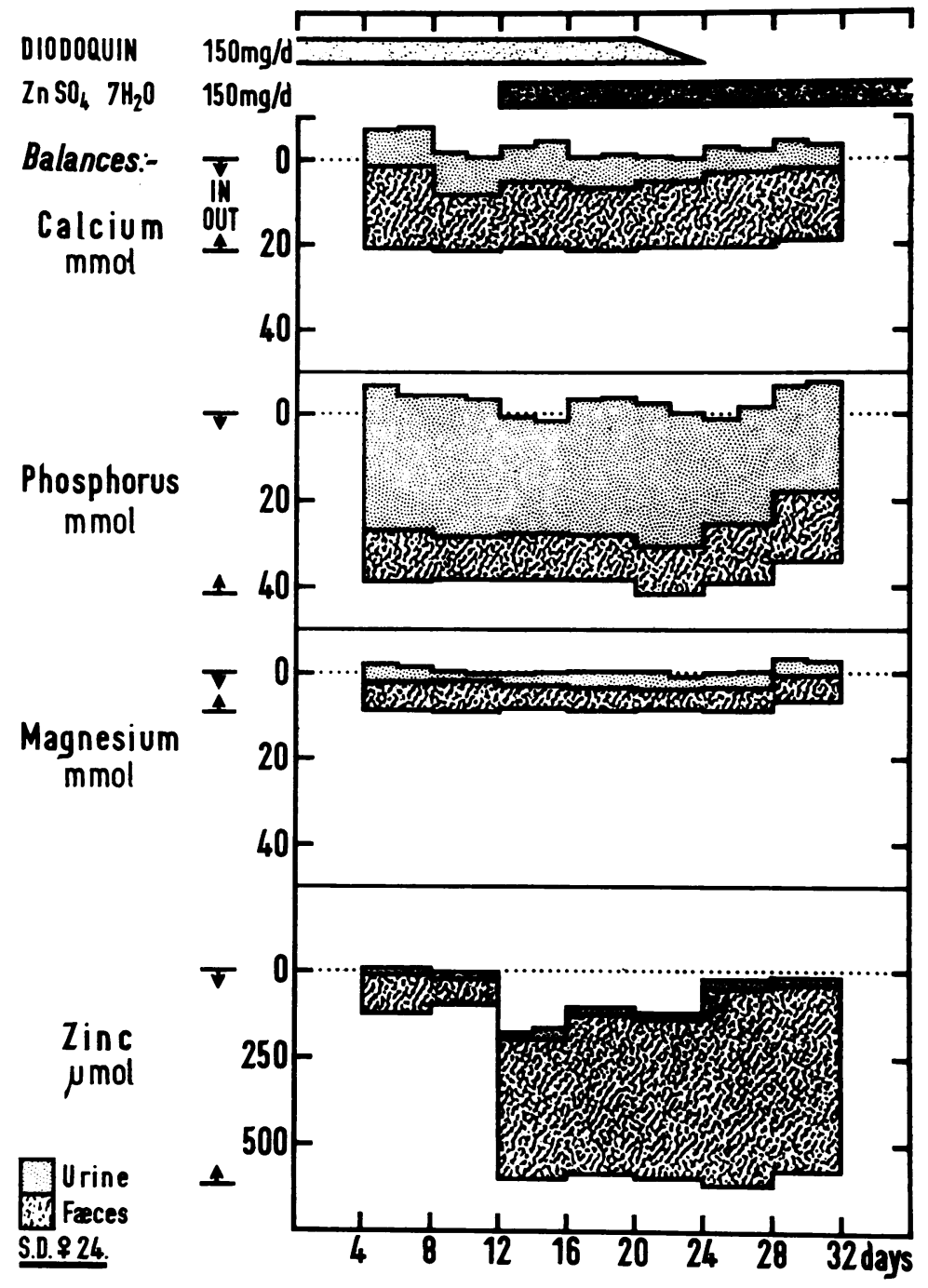

Fig. 1 Results of metabolic balance studies carried out on a patient with acrodermatitis enteropathica from 7 April to 4 May 1975, showing variations in the retention of calcium, magnesium, phosphorus and zinc during a change of treatment from di-iodohydroxyquinoline (Diodoquin) to zinc sulphate.

\section{Methods}

\section{BALANCE TECHNIQUE}

Standard metabolic balance techniques were modified by the use of cuprous thiocyanate as a continuous internal faecal marker (Dick, 1969) in addition to carmine markers taken with breakfast at the beginning of each four-day period. The diet was chosen by the patient and was kept constant throughout the study. An additional quarter of each meal was weighed out and kept for chemical analysis.

Calcium, magnesium, copper, and zinc wère estimated by atomic absorptions pectroscopy ${ }^{1}$ and phosphorus estimations were made by a modified automated version of the method of Fiske and Subbarow (1925).

During the first two four-day periods the patient was given di-iodohydroxyquinoline $(1500 \mathrm{mg} /$ day $)$; during the second two periods the zinc sulphate $\left(\mathrm{ZnSO}_{4} .7 \mathrm{H}_{2} \mathrm{O} ; 150 \mathrm{mg} /\right.$ day $)$ was given in tablet form together with the di-iodohydroxyquinoline. During the fifth period the di-iodohydroxyquinoline 'Plasma zinc estimations were made by the proposed method of Momcilović et al. (1975). 


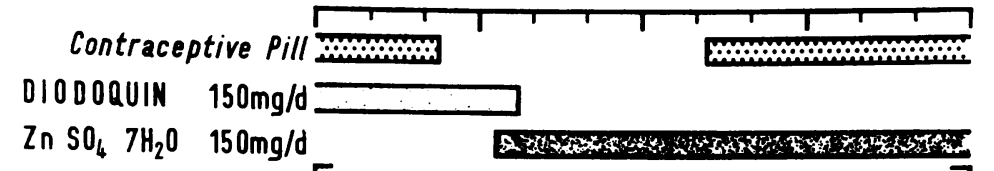

$2 \mathrm{nSO}_{4} \quad \mathrm{H}_{2} \mathrm{O} \quad 150 \mathrm{mg} / \mathrm{d}$
S.0. 924.

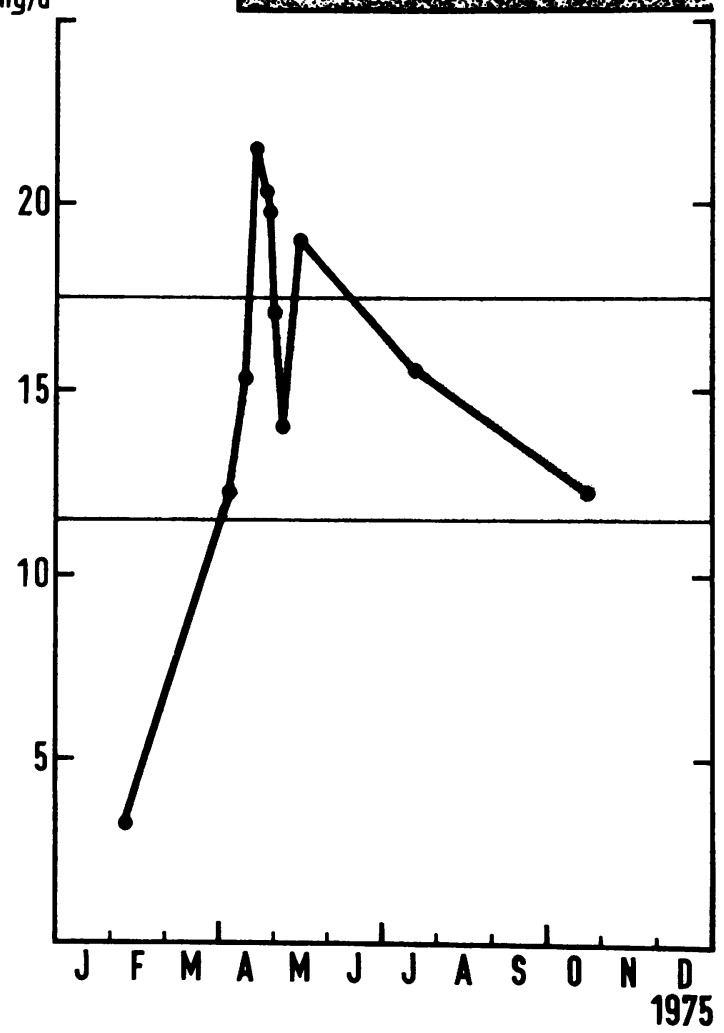

Plasma Zinc $\mu \mathrm{mol} / \mathrm{l}$
Fig. 2 Plasma zinc levels measured in a patient with acrodermatitis enteropathica while taking the contraceptive pill and during change of treatment from di-iodohydroxyquinoline (Diodoquin) to zinc sulphate. was gradually discontinued, and in the last two periods the patient was receiving zinc sulphate therapy only.

\section{Results}

The balance results obtained are shown in Figure 1. These charts were constructed using the method chosen by Albright and Reifenstein (1948). The results obtained for the calcium, magnesium, and phosphorus balances do not show any significant changes with the variations in treatment during the course of the balance studies.

During the first two periods of the balance the patient was in approximately zero balance for zinc. On starting supplementation with zinc sulphate the balance became approximately $110 \mu \mathrm{M} /$ day positive. On stopping the di-iodohydroxyquinoline the amount of retention fell to approximately $30 \mu \mathrm{M} /$ day.
The plasma zinc was initially very low $(3 \cdot 2 \mu \mathrm{M} / \mathrm{l})$, but after the contraceptive pill was stopped it rose sharply to within the lower limit of normal (Fig. 2). During zinc therapy the level rose again, to reach a maximum of $21.4 \mu \mathrm{M} / 1$ after six days. Over the next two months the plasma zinc varied greatly, but the level has now returned into the normal range $(11 \cdot 5-17 \cdot 5 \mu \mathrm{M} / \mathrm{l})$.

\section{Discussion}

The supplementation of the patient's diet with zinc sulphate gave the expected clinical response and confirmed that the disease in this patient was characterised by a deficiency of zinc. The patient retained approximately $1.8 \mathrm{mM}$ of zinc during the 20 days of zinc supplementation. Thus it seems likely that the deficiency of zinc in acrodermatitis enteropathica is relatively small as it has been reported that 
the human body contains a total of between 21.4 and $35 \cdot 2 \mathrm{mM}$ of zinc (Reinhold, 1975).

The large increase in the retention of zinc on starting zinc supplementation was not maintained at such a high level when the di-iodohydroxyquinoline therapy was withdrawn (see Fig. 1). The urinary zinc level also fell when the di-iodohydroxyquinoline was stopped, thus suggesting that the role of di-iodohydroxyquinoline in this disease is to increase the absorption of zinc from the gut.

The results of the calcium, magnesium, and phosphorus balances did not show any consistent changes throughout the period of study (Fig. 1). The patient was for some unknown reason in negative calcium balance throughout the study, even though her urine calcium fell to a normal level $(5.6 \mathrm{mM} / 24 \mathrm{~h})$ after the beginning of zinc sulphate therapy. The phosphorus and magnesium balances varied around zero throughout.

It has been noted that the use of oral contraceptives causes a decrease in the plasma zinc levels (Halsted et al., 1968), and it seems likely that the increase in plasma zinc noted before supplementation with zinc sulphate was a 'rebound' effect caused by withdrawal of the Minilyn (Fig. 2). The reason for the subsequent instability after supplementation with zinc sulphate is unknown but may be related to the time at which the blood samples were drawn, or to what foods were being eaten when the zinc sulphate was taken. It has recently been shown (Pécoud et al., 1975) that the plasma zinc levels rise after large doses of oral zinc sulphate and that the rise is dependent upon the type of foods with which the zinc supplements are taken.

After several weeks of zinc sulphate therapy the patient had a complete remission of symptoms. She has now been restarted on the contraceptive pill which appears to have caused a fall in the plasma zinc to $12 \cdot 2 \mu \mathrm{M} / 1$. A mild recurrence of the skin rash has recently occurred for a short period but had disappeared at the time of her latest follow-up (9 February 1976).

I thank the late Professor C. E. Dent and Miss J. M. Round for help and encouragement, Mr P. Knowles for expert technical assistance, and Miss M. Lilburn, the Metabolic Ward dietitian, for her continuous cooperation.

\section{References}

Albright, F. and Reifenstein, E. C., Jr. (1948). The Parathyroid Glands and Metabolic Bone Disease, p. 309. Williams and Wilkins, Baltimore; Baillière, London.

Barnes, P. M. and Moynahan, E. J. (1973). Zinc deficiency in acrodermatitis enteropathica. Proc. roy. Soc. Med., 66, 327-329.

Calhoun, N. R., Smith, J. C., Jr., and Becker, K. L. (1974). The role of zinc in bone metabolism. Clin. Orthop. relat. Res., 103, 212-234.

Delves, H. T., Harries, J. T., Lawson, M. S., and Mitchell, J. D. (1975). Zinc and Diodoquin in acrodermatitis enteropathica (Letter). Lancet, 2, 929.

Dick, M. (1969). Use of cuprous thiocyanate as a shortterm continuous marker for faeces. Gut, 10, 408-412.

Fiske, C. H. and Subbarow, Y. (1925). The colorimetric determination of phosphorus. J. biol. Chem., 66, 375-400.

Halsted, J. A., Hackley, B. M., and Smith, J. C., Jr. (1968). Plasma-zinc and copper in pregnancy and after oral contraceptives (Letter). Lancet, 2, 278-279.

Hare, P. J. and Schlesinger, B. E. (1955). Acrodermatitis enteropathica. Proc. roy. Soc. Med., 49, 231-234.

Lombeck, I., Schnippering, H. G., Ritzl, F., Feinendegen, L. E., and Bremer, H. J. (1975). Absorption of zinc in acrodermatitis enteropathica (Letter). Lancet, 1, 855.

Momčilović, B., Belonje, B., and Shah, B. G. (1975). Effect of the matrix of the standard on results of atomic absorption spectrophotometry of zinc in serum. Clin. Chem., 21, 588-590.

Moynahan, E. J. (1974). Acrodermatitis enteropathica: A lethal inherited human zinc-deficiency disorder (Letter). Lancet, 2, 399-400.

Moynahan, E. J. (1975). Acrodermatitis enteropathica in two siblings treated with zinc sulphate supplements alone. Proc. roy. Soc. Med., 68, 276.

Neldner, K. H. and Hambidge, K. M. (1975). Zinc therapy of acrodermatitis enteropathica. New Engl. J. Med., 292, 879-882.

Pécoud, A., Donzel, P., and Schelling, J. L. (1975). Effect of foodstuffs on the absorption of zinc sulfate. Clin. Pharmacol. and Ther., 17, 469-474.

Reinhold, J. G. (1975). Trace elements-a selective survey. Clin. Chem., 21, 476-500. 